\title{
Elasticidade-preço da Demanda por Etanol no Brasil: como renda e preços relativos explicam diferenças entre estados
}

\author{
Veronica Fernandez Orellano ${ }^{1}$, Alberto De Nes de Souza ${ }^{2}$ e \\ Paulo Furquim de Azevedo $^{3}$
}

Resumo: Este artigo estuda a demanda por etanol no Brasil no período 20012009, considerando as características regionais de renda e de preços relativos. Essas características explicam variação relevante na elasticidade-preço da demanda, aspecto até então desconsiderado em estudos anteriores. Foi estimado um modelo econométrico a partir de um painel de dados estaduais mensais, no qual variáveis instrumentais foram usadas para controlar a endogeneidade na análise da demanda. Conclui-se que a demanda é mais elástica em estados mais pobres e em que o preço relativo está próximo a 70\%, a taxa técnica de substituição entre etanol e gasolina, parâmetro relevante para as decisões de consumo de proprietários de veículos flex-fuel. Essas regiões apresentam maiores elasticidades-preço da demanda, em última análise, por conta de diferenças logísticas e tributárias, as quais definem o preço relativo. Esses resultados diferem daqueles obtidos por Salvo e Huse (2013), pois identificam diferenças regionais que independem da heterogeneidade das preferências dos consumidores, mas decorrem da configuração logística e de renda. Os resultados sugerem implicações para as políticas tributária e de infraestrutura logística, as quais, ao afetarem o nível de preços relativos de etanol e gasolina, afetam a sensibilidade da demanda com relação às variações de preço.

Palavras-chaves: Elasticidade da demanda, etanol, efeito renda, diferenças regionais.

Abstract: This article analyzes the demand for ethanol in Brazil, from 2001 to 2009, taking into account regional differences in regard of relative price and per capita income. These elements explain significant variability of demand elasticities across regions, a result not yet addressed by the related literature. By means of a panel with monthly data at the state level, we estimate an econometric model with instrumental variables to control endogeneity. We found that the demand is more elastic in poorer states and in regions whose relative price is closer to $70 \%$, the technical rate of substitution between ethanol and gasoline, which is expected to trigger the demand decision of owners of flex-fuel vehicles.

1 Professora da FGV-EESP. E-mail: vfernandezorellano@gmail.com

2 Mestre pela FGV-EESP. E-mail: alberto.nes-souza@itau-unibanco.com.br

3 Professor da FGV-EESP e Pesquisador do CNPq. E-mail: paulo.azevedo@fgv.br 
Those regions present higher demand price-elasticity, for ultimately logistic and tributary reasons, that determines relative prices. Results differ from those from Salvo and Huse (2013), since our model explain regional differences that do not need to rely on consumer preference heterogeneity, but occur because of logistics and income regional distribution. Our findings suggest implications for taxation and logistic infrastructure policies, which directly affect the relative prices of ethanol and gasoline, and, therefore, indirectly influence the demand elasticity.

Key-words: Demand elasticity, ethanol, income effect, regional differences.

Classificação JEL: Q41.

\section{Introdução}

Poucos assuntos são tão consensuais como a inevitável mudança na matriz energética mundial, particularmente para fins de transporte automotivo (CHICHILNISKY, 2006; GREENPEACE, 2010; WWF, 2011). Seja pelo esgotamento das reservas de petróleo, prevista para as próximas décadas, seja pelas consequências acumuladas do consumo de combustíveis fósseis sobre o meio ambiente, formas de energia renovável, entre elas e em particular biocombustíveis, estão na ordem do dia. Há, portanto, grande interesse em entender o modo de funcionamento desses mercados, um conhecimento necessário para a elaboração de estratégias empresariais e, sobretudo, de políticas públicas. O Brasil oferece um laboratório particularmente interessante para essa espécie de estudos, não só por ser o espaço do mais antigo programa de etanol automotivo em larga escala, mas, em especial, por contar com uma frota de veículos flex-fuel já expressiva, a qual permite o estudo de padrões de consumo em situações em que o consumidor pode arbitrar entre diferentes combustíveis.

Este artigo estuda a demanda por etanol no Brasil no período 2001-2009, utilizando diferenças regionais para captar aspectos ainda pouco explorados pela literatura e que conduzem a padrões de demanda bastante distintos. Em par- ticular, diferenciais logísticos e tributários resultam em grande variabilidade dos preços relativos entre etanol e gasolina entre regiões, o que pode resultar em parâmetros da demanda substancialmente diferentes, mensurados por meio das elasticidades própria e cruzada. As diferenças regionais também permitem captar o efeito do nível de renda per capita sobre as elasticidades-preço, de tal modo que é possível identificar que a renda não apenas afeta o nível de demanda (via elasticidade-renda da demanda), mas também e substancialmente a sensibilidade da demanda em relação a preços (efeito substituição).

Para lidar com o clássico problema de identificação da demanda, foram propostos alguns modelos de estimação que usam variáveis instrumentais. Além disso, para analisar as diferenças regionais, as unidades federativas foram separadas em dois grupos no que diz respeito ao preço relativo etanol-gasolina, pois nem todos os estados brasileiros têm preço relativo etanol-gasolina numa faixa próxima ao valor crítico de $70 \%$, dadas as diferenças de distância com relação à região produtora.

A relação entre o preço do etanol e o preço da gasolina apresenta grandes diferenças entre unidades federativas. Enquanto em São Paulo a média dessa razão para o período 2001-2009 foi inferior a 0,55 (55\%), no Pará, essa média foi de 0,8 (80\%). Isto é, em São Paulo, a paridade etanol- 
-gasolina esteve quase sempre abaixo dos $60 \%$, o que, a princípio, faz do etanol uma escolha quase sempre mais vantajosa para o consumidor dessa região - admitindo que é economicamente mais vantajoso utilizar o etanol sempre que o seu preço for inferior a $70 \%$ do preço da gasolina C. No estado do Pará, por sua vez, a paridade de preços é suficientemente alta para que um proprietário de automóvel flex-fuel opte quase sempre pela gasolina, mesmo quando há pequenas mudanças nos preços relativos. Finalmente, em estados como Bahia e Minas Gerais, a paridade está quase sempre numa faixa entre $65 \%$ e $75 \%$, o que deve levar a mudanças frequentes na escolha dos consumidores.

Este estudo considera que as elasticidades-preço do etanol deveriam ter maior magnitude, ceteris paribus, em estados como Minas Gerais e Bahia, uma vez que, neles, pequenas variações nos preços relativos são suficientes para a modificação da escolha do consumidor. Para testar esta proposição, este trabalho classificou os estados em faixas de acordo com o preço relativo médio entre etanol e gasolina. Como existe uma correlação entre renda per capita e o preço relativo etanol-gasolina nas unidades federativas, foram também criadas faixas de renda per capita, como forma de controlar e analisar esses dois efeitos.

Finalmente, na esteira de outros estudos realizados para o Brasil (SERIGATI et al., 2010; FREITAS e KANEKO, 2011; SANTOS, 2013), procurou-se levar em consideração que o incremento da participação da frota flex-fuel provavelmente alterou as elasticidades no período recente. Desse modo, o estudo foi feito separadamente para dois períodos distintos, levando-se em conta o crescimento da frota de veículos com motores flex-fuel.

Este artigo está estruturado em mais seis seções além desta introdução. A segunda seção expõe brevemente a evolução recente da estrutura do mercado de combustíveis para veículos leves no Brasil. Na seção seguinte apresenta-se uma revisão bibliográfica de trabalhos empíricos que analisaram a demanda por etanol. A quarta seção define o modelo econométrico estimado e a quinta seção descreve os dados. Por fim, a sexta seção apresenta os resultados obtidos e a última traz as conclusões e indica direções para trabalhos futuros.

\section{O mercado brasileiro de combustíveis para veículos leves: evolução recente}

A possibilidade de o consumidor escolher entre a gasolina e o etanol hidratado, ou até mesmo uma combinação entre esses, resultou numa nova dinâmica no mercado brasileiro. Os primeiros carros chamados bicombustíveis começaram a ser produzidos no primeiro trimestre de 2003, pela Volkswagen, mas o carro bicombustível, também chamado de flex-fluel, só começou a ter relevância na frota de veículos automotivos cerca de dois anos depois, como mostra a Figura 1.

A partir de 2004, pode-se observar uma queda na participação de veículos a gasolina e a etanol na frota brasileira, decorrente do início das vendas de veículos flex-fuel em 2003, cuja evolução da frota é apresentada na Figura 2. Observa-se que, a partir de agosto de 2006, a participação de veículos flex-fuel na frota passou a ser maior que a participação de veículos movidos a etanol, atingindo aproximadamente $40 \%$ do total da frota em outubro de 2009.

As relações de preço entre etanol hidratado e gasolina variam consideravelmente entre os estados brasileiros, em decorrência da espacialização da produção e do consumo, das condições logísticas de transporte e armazenagem e de diferenciais tributários em impostos estaduais. Essas diferenças nos preços relativos vão se traduzir, por sua vez, em comportamentos regionalmente distintos da demanda e de padrões de substituição entre etanol e gasolina, fenômeno tanto mais importante quanto maior for a participação dos veículos flex-fuel no total da frota. Em outras palavras, mesmo se admitindo homogeneidade de consumidores, há motivos para que os parâmetros da demanda se diferenciem regionalmente. Naturalmente, diversos estudos de demanda de etanol ou gasolina, feitos para o Brasil, por utilizarem séries de dados sem variabilidade regio- 
Figura 1. Vendas de automóveis flex-fuel no mercado interno

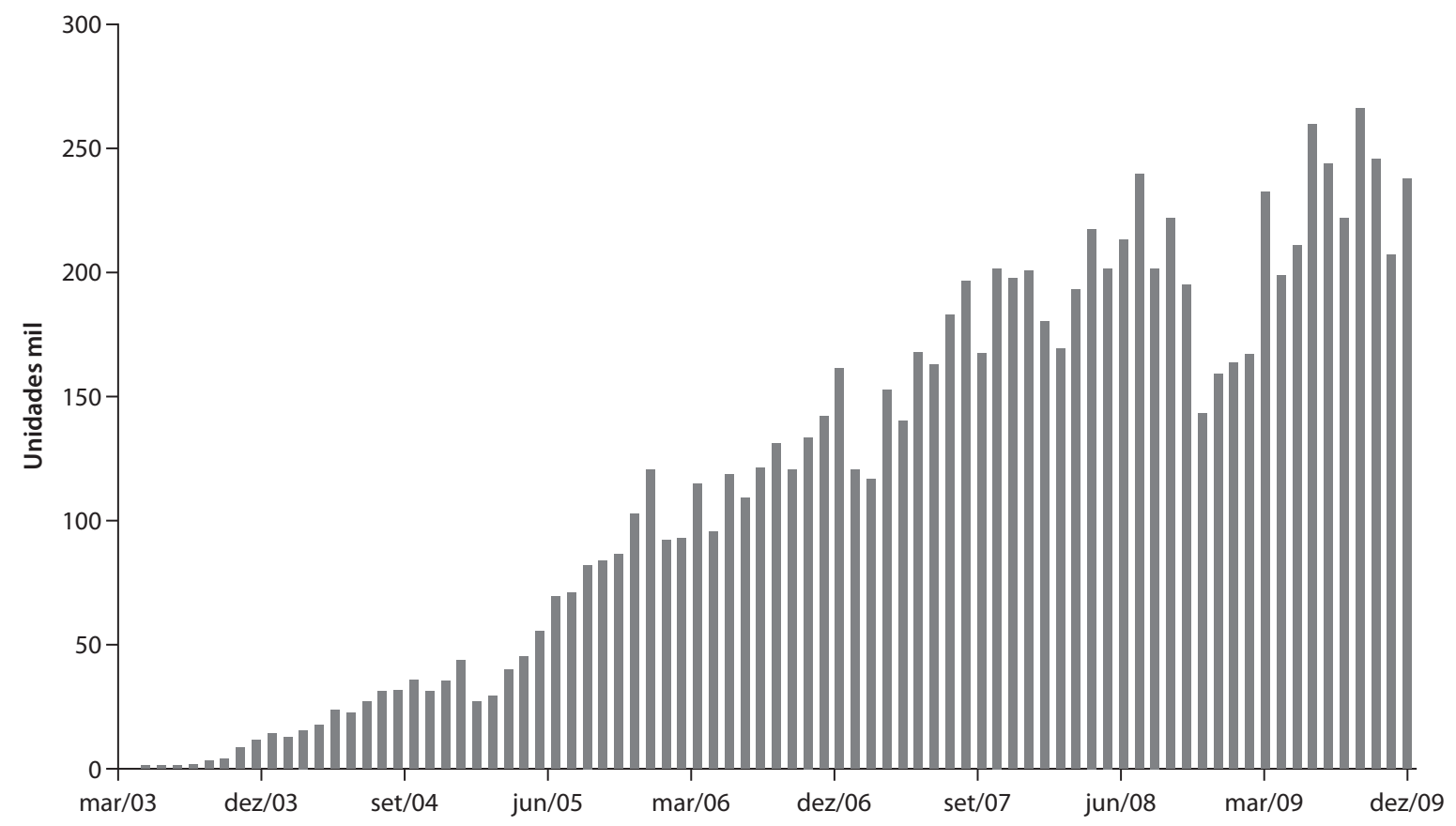

Fonte: Fenabrave - Elaboração própria.

Figura 2. Distribuição da frota do Ciclo de Otto $^{1}$ por combustível

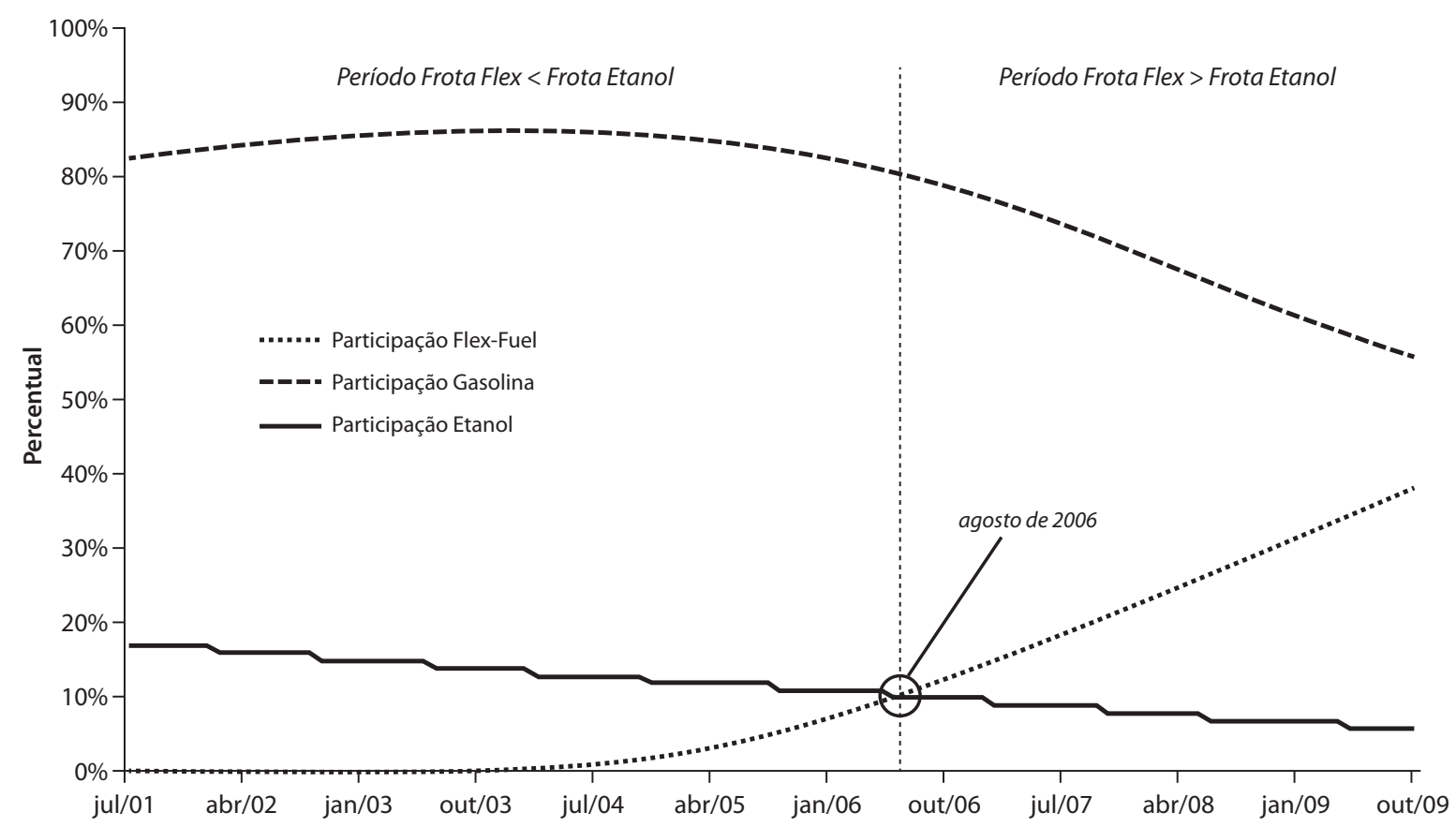

Nota: A frota foi calculada pelos autores com a metodologia MCT (2006).

Fonte: Dados da Anfavea - Elaboração própria.

1 Ciclo de Otto é um ciclo termodinâmico, que idealiza o funcionamento de motores de combustão interna de ignição por centelha. Motores baseados neste ciclo equipam os automóveis de passeio movidos a gasolina e etanol, não incluindo aqueles movidos a diesel. 
nal, não puderam incorporar essa característica em sua análise (e.g. BACCHI, 2005; FREITAS e KANEKO, 2013).

A introdução da tecnologia flex-fuel criou um segmento de mercado capaz de arbitrar, instantaneamente e sem custos, entre o consumo de gasolina e de etanol, o que, na ausência de heterogeneidade nas preferências dos consumidores, torna esses produtos substitutos quase perfeitos, diferindo apenas pela autonomia do veículo e características ambientais. Dado que o diferencial de rendimento técnico entre etanol e gasolina é de cerca de $70 \%$, com pequenas variações conforme o modelo do veículo (MAISTRO e ASAI, 2006), os proprietários de veículos flex-fuel tendem a modificar a sua escolha se e somente se o preço relativo ultrapassar essa proporção, a qual define situações em que o consumo de etanol ou de gasolina é mais vantajoso.

Esta característica confere uma importante consequência para as estimações de demanda por etanol. Em áreas em que o preço relativo tende a ser bastante inferior a $70 \%$, pequenas variações nos preços da gasolina ou do etanol não implicam mudança relevante da quantidade consumida, visto que o etanol permanece como a escolha racional para o detentor de um automóvel flex-fuel. Isso significa que, nessas regiões, a demanda tende a ser mais inelástica em relação ao preço. $\mathrm{O}$ mesmo ocorre nas regióes em que o preço relativo médio, por questões logísticas ou tributárias, é bastante superior a $70 \%$, de tal modo que os detentores de veículos flex-fuel tendem a optar pela gasolina, independentemente de pequenas variações no preço de cada um dos combustíveis. Finalmente, nas regiões em que o preço relativo tende a se situar próximo a 70\%, pequenas variações de preço do etanol ou da gasolina podem modificar o combustível escolhido pelos consu- midores, de tal modo que a demanda tenderá a ser mais elástica em relação aos preços.

Este efeito é, contudo, mitigado pela composição da frota de veículos automotivos, que ainda conta com elevada participação de automóveis que utilizam apenas um combustível, e pela existência de alguma heterogeneidade nas preferências dos consumidores sobre, por exemplo, questões ambientais. Ainda que mitigado por estes fatores, a frota flex-fuel é suficientemente grande para que tais efeitos sejam observados e, portanto, esta proposição seja testada empiricamente.

A Figura 3 apresenta os preços relativos médios etanol/gasolina no período 2001-2009, para todos os estados da federação (eixo das abscissas), os preços médios do etanol hidratado (eixo das ordenadas) e o volume de consumo de etanol, dado pelo tamanho relativo das circunferências que representam cada estado. Pode-se notar que há grande variabilidade dos preços relativos médios, o que, conforme argumentado, deve resultar em diferentes elasticidades-preço da demanda. Além disso, nota-se que os preços do etanol são positivamente correlacionados com os preços relativos entre etanol e gasolina, o que resulta de uma distribuição espacial das refinarias de petróleo mais equilibrada e, portanto, menor variabilidade no preço da gasolina por questões logísticas.

Devido às distintas situações de paridade no Brasil, é esperada a observação de menores elasticidades próprias e cruzadas (em módulo) nos estados cujo preço médio relativo etanol-gasolina está muito acima ou muito abaixo do valor crítico de $70 \%$. Nesses estados, pequenas alterações do preço relativo não deveriam provocar um movimento expressivo de substituição de um combustível pelo outro. 
Figura 3. Paridade média etanol-gasolina de 2001-2009, por estado

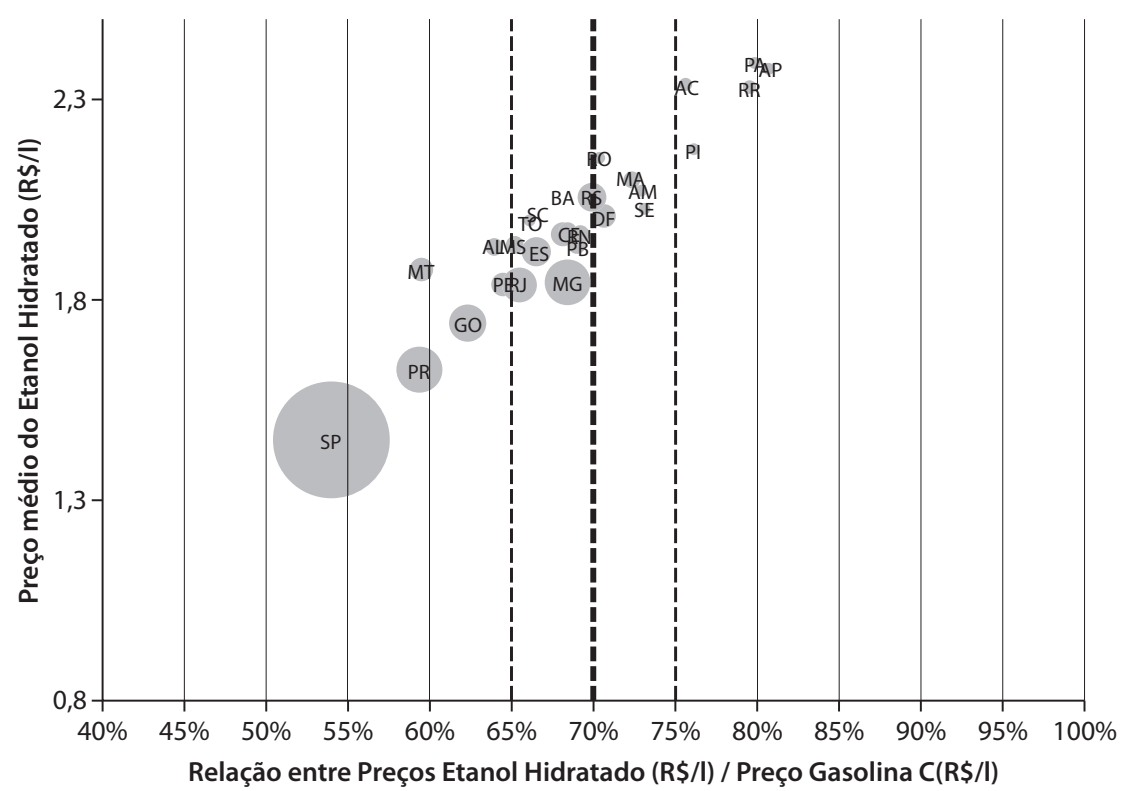

Notas: (i) As bolhas são proporcionais ao consumo médio de etanol de jul/2001 a dez/2009; (ii) Os preços foram expressos em Reais de dez/2009; (iii) a linha pontilhada mais grossa representa a paridade etanol-gasolina de $70 \%$; as duas linhas pontilhadas mais finas delimitam as faixas entre $65 \%$ e $75 \%$.

Fonte: Dados da ANP - Elaboração própria.

\section{Estudos empíricos sobre a demanda por etanol}

Há diversos estudos que analisam a demanda por gasolina nos mais variados países e por diferentes métodos estatísticos (BURNQUIST e BACCHI, 2002; RAMANATHAN, 1999; RODRIGUEZ, 2006). Em contrapartida, há um número relativamente pequeno de trabalhos sobre a demanda por etanol, o que se deve à evidente predominância mundial da gasolina como combustível para veículos leves, sendo o etanol frequentemente utilizado na forma de mandatos que estabelecem adição obrigatória e fixa à gasolina vendida ao consumidor final. Mais recentemente, com a difusão do E85 nos EUA e o crescente interesse pela experiência brasileira de etanol hidratado, uma série de estudos estimou a demanda por este combustível. Esta seção traz uma síntese desta literatura, com o objetivo de identificar a contribuição do estudo empírico proposto neste artigo.
Os estudos feitos para os EUA podem tratar da demanda por etanol por distribuidoras, como Luchansky e Monks (2009), ou pelo consumidor final, na forma de E85, como em Anderson (2011). Luchansky e Monks (2009) estimaram a demanda e a oferta de etanol para o mercado norte-americano utilizando técnicas de regressão em dois estágios. Os instrumentos exógenos (deslocadores de oferta) utilizados para identificar a equação de demanda por etanol são o preço do milho e o preço do óleo de milho, uma vez que o etanol norte-americano é produzido a partir do milho. Os resultados encontrados foram que a demanda por etanol é elástica em relação ao seu preço com coeficientes variando de $-1,605$ até $-2,915$. Para a elasticidade-preço cruzada etanol-gasolina foram obtidos coeficientes variando de $-2,080$ até $-3,606$, sendo estes negativos devido ao grande uso do etanol como aditivo da gasolina no mercado americano.

Anderson (2011), por sua vez, estima a elasticidade da demanda pelos consumidores finais de 
E85, o que lhe permite estimar a magnitude do prêmio que estes estariam dispostos a pagar pelas vantagens ambientais do etanol frente à gasolina. Seus resultados indicam que há considerável heterogeneidade entre consumidores, o que se materializa em elevada variação do prêmio que se aceita pagar pelas vantagens ambientais do etanol. Salvo e Huse (2013), embora não estimem a elasticidade-preço da demanda, também identificam heterogeneidade nas preferências dos consumidores brasileiros, associadas a características demográficas e regionais, que revelam maior disposição a pagar pelo etanol entre os consumidores jovens e presumivelmente identificados com questões ambientais ou de identificação com a produção de etanol.

No caso do mercado brasileiro, Sordi (1997) estudou a demanda por álcool hidratado carburante no período 1980-1995 com dados mensais. $\mathrm{O}$ autor baseou sua análise em dois modelos de demanda, que diferiam no tratamento da oferta como exógena ou endógena. $\mathrm{O}$ autor conclui que, nesse período, em que ainda não tinham sido lançados os veículos flex-fuel no Brasil, a demanda por etanol era inelástica com relação ao preço e à renda.

Bacchi (2005) estimou a relação dos preços do setor sucroalcooleiro com a gasolina $C$ para o período de julho de 2001 a agosto de 2004 por meio da metodologia de Autorregressão Vetorial (VAR). Os resultados apontam que as variações do preço da gasolina $\mathrm{C}$ ao consumidor têm efeito imediato e de grande magnitude sobre o preço do álcool hidratado, indicando elevado grau de substituibilidade do primeiro produto pelo segundo. Pelo método empregado, foi possível verificar a transmissão dos preços de gasolina, etanol e açúcar, mas, dada a ausência de dados de quantidade consumida, não foi possível, neste trabalho, estimar as elasticidades da demanda por etanol.

Contando já com os efeitos da frota flex-fuel, Farina et al. (2010) estimam a elasticidade-preço do etanol por meio de séries temporais, utilizando o modelo VEC. Diferente do encontrado por Sordi (1997), as autoras identificam elevada elasticidade da demanda por etanol, bem como elevada elasticidade-cruzada da quantidade consumida por etanol em relação a variações do preço da gasolina. Esses resultados são esperados frente ao crescimento da relevância da frota de veículos flex-fuel, que faz aumentar o grau de substituição entre esses produtos.

Em uma abordagem diferente, baseada em dados em painel, Serigati, Correia e Perosa (2010) estimaram, por meio de uma regressão em três estágios, as curvas de demanda e de oferta de álcool hidratado, bem como a curva de demanda por açúcar entre julho de 2001 e abril de 2009. Os resultados sugerem que houve aumento significativo na elasticidade-preço da demanda do álcool hidratado e na elasticidade cruzada entre o álcool e a gasolina, após a introdução de veículos flex-fuel, consistente com a hipótese de aumento do grau de substituibilidade entre os dois combustíveis.

Resultados consistentes são encontrados por Freitas e Kaneko (2011) e por Santos (2013), que identificam aumento da elasticidade-preço da demanda por etanol hidratado no Brasil, que decorreria do aumento consistente da frota flex-fuel após 2003. Freitas e Kaneko (2011) destacam que os valores das elasticidades de curto e longo prazo são semelhantes, o que decorreria da capacidade de um grupo relevante de consumidores arbitrar entre os dois combustíveis instantaneamente, sem a necessidade de troca de veículo. Santos (2013) identifica que a demanda por etanol é mais elástica do que a de combustíveis alternativos, como a gasolina e o gás natural, o que faz desse combustível aquele que mais se ajusta a choques e define o dinamismo do mercado brasileiro de combustíveis.

Santos (2013) e Santos e Faria (2012) também observam que a maioria dos estudos sobre demanda de combustíveis líquidos apoia-se em métodos de séries de tempo, que não permitem explorar a variabilidade espacial dos preços e quantidades demandadas de combustíveis. ${ }^{4}$ Estes trabalhos utilizam uma estrutura de dados

4 Exceção feita a Serigati et al. (2010), que também utilizam um painel de estados como estrutura de dados. 
em painel com finalidade de controlar a correlação espacial entre os preços do etanol, mitigando eventual problema de viés que poderia decorrer da omissão desse controle.

Nenhum desses trabalhos, contudo, explora as diferenças regionais como variável-foco para explicar diferenças nas elasticidades-preço da demanda. Conforme argumentado na seção 2 deste artigo, as condições logísticas e tributárias resultam em preços relativos médios distintos conforme a região do País. O nível do preço relativo médio, por sua vez, deve afetar a magnitude da elasticidade-preço da demanda, sendo esta maior nas regióes em que o preço relativo for próximo ao parâmetro de $70 \%$. Este trabalho traz como contribuição o teste desta proposição, ainda não explorada pela literatura.

\section{O modelo estimado para a demanda por etanol}

Modelos de estimação de demanda usando dados agregados apresentam um problema de identificação, uma vez que os dados sobre vendas e preços observados correspondem a pontos de equilíbrio de mercado. Isto é, nesses modelos, o pesquisador tem que enfrentar um clássico problema de endogeneidade, uma vez que os preços são variáveis explicativas correlacionadas com o termo de erro da regressão. Uma forma de contornar essa situação é utilizar métodos de variáveis instrumentais por meio da regressão em dois estágios (MQ2E), a qual torna os parâmetros identificáveis ao utilizar deslocadores da oferta como variáveis instrumentais para os preços, e deslocadores de demanda como controles.

Neste estudo, assim como em Luchansky e Monks (2009), variáveis fortemente relacionadas aos custos de produção (inclusive ao custo de oportunidade) foram usadas como variáveis instrumentais, sendo esses instrumentos clássicos na análise de demanda por serem deslocadores de oferta. Além disso, também foi usada como variável instrumental a média do preço do etanol nos estados vizinhos. Como colocam Huse e
Salvo (2005), ao lidar com dados de painel, preços de outras regióes podem servir como instrumentos para o preço em determinada região. A ideia é que os preços de um mesmo produto em diferentes regiões têm um componente de custos comum a todas as regiões, mas um componente de demanda específico para cada região. Assume-se que os componentes não observados de demanda específicos a cada região são independentes entre si.

Equações de demanda foram estimadas separadamente para dois períodos distintos: julho de 2001 a agosto de 2006 e setembro de 2006 a dezembro de 2009. Isso foi feito para levar em consideração a grande alteração ocorrida no mercado nacional com a introdução dos veículos flex-fuel, sendo que agosto de 2006 é a data a partir da qual a participação de veículos flex-fuel na frota passou a ser maior que a participação de veículos movidos a etanol, conforme foi destacado na segunda seção.

Para explorar as diferenças regionais, decorrentes de nível de renda e condições logísticas, os estados foram divididos em dois grupos, com renda per capita acima (ricos) e abaixo (pobres) da média nacional. Isso foi feito separadamente para os dois períodos de tempo investigados e os estados classificados como ricos praticamente não mudam. Como pode ser visto na Tabela A1 do anexo estatístico, apenas o estado de Minas Gerais foi promovido, passando a ser classificado como rico. Os estados de Roraima e Amapá, ao contrário, caíram de status e passaram a ser classificados como pobres. Além disso, foram levadas em consideração as diferenças entre os estados no que diz respeito à razão entre o preço do etanol e o da gasolina. Por razões já citadas na segunda seção deste artigo, é natural supor que o consumidor substituirá mais facilmente gasolina por etanol e vice-versa quando o preço do etanol estiver próximo à paridade de $70 \%$ do preço da gasolina C.

Na Tabela 1, os estados são classificados de acordo com a paridade média para cada período estudado. Foram separados os estados com paridade média dentro da faixa de $65 \%$ a $75 \%$ 
Tabela 1. Unidades federativas e faixas no período de 2001-2009

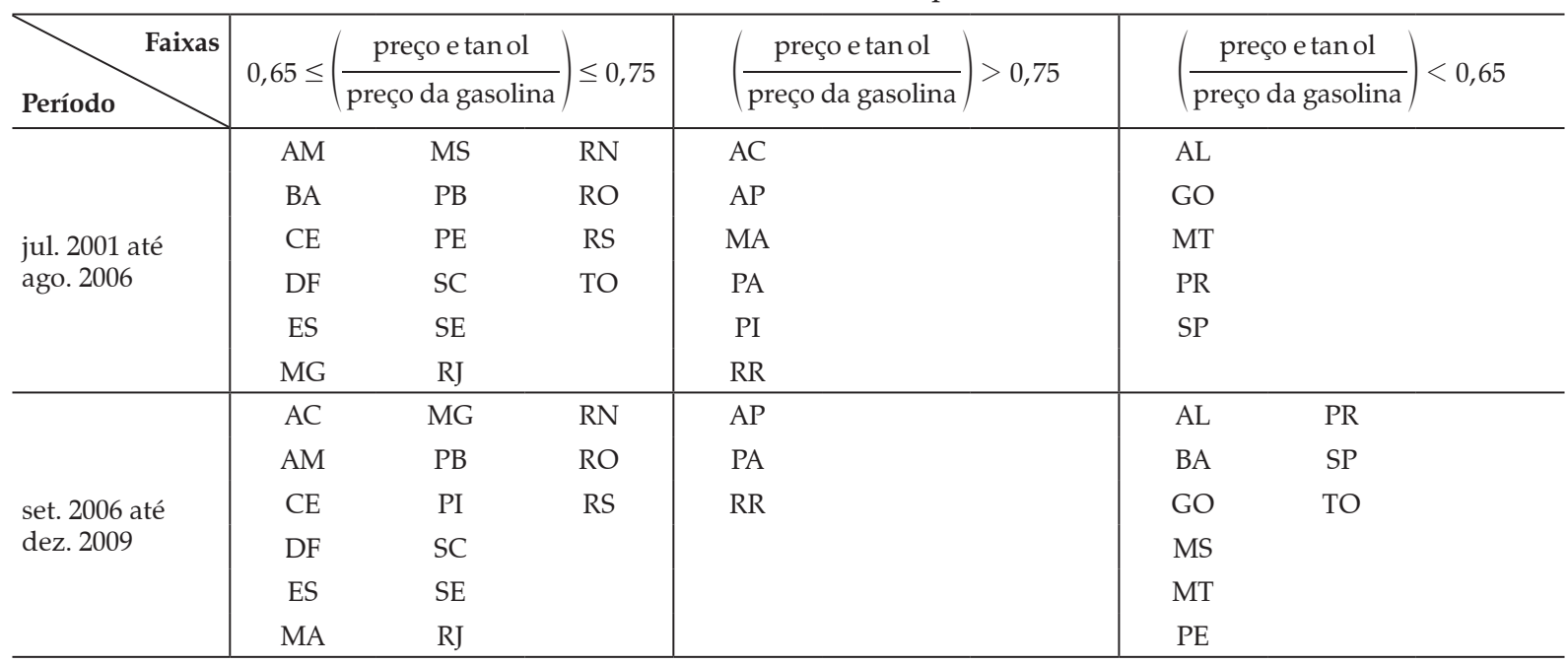

Fonte: ANP. Elaboração própria.

dos demais - tanto com paridade abaixo quanto acima dessa faixa.

As relações de preço etanol-gasolina nos estados possuem desvios padrão pequenos (Tabela A2 em anexo), reforçando a ideia de que a utilização da média dessa variável como indicador para a criação das dummies de faixa é uma opção apropriada.

A partir dessas duas classificações dos estados - ricos e pobres e dentro e fora da faixa de paridade -, foram construídas quatro variáveis binárias que permitiram testar os diferenciais de elasticidade de acordo com a renda e a faixa de paridade. Essas variáveis, definidas na próxima seção, separam os grupos de estados ricos/dentro da faixa, pobres/dentro da faixa, ricos/fora da faixa e pobres/fora da faixa.

Essa estratégia foi necessária porque há uma correlação entre renda per capita e o preço relativo etanol-gasolina nos estados, como se nota na Figura 4, a seguir. A existência dessa relação dificulta a identificação de diferenças de elasticidade-preço de acordo com a renda apenas a partir da separação entre estados ricos e pobres, assim como a identificação de diferenças de elasticidade-preço de acordo com a faixa de paridade apenas a partir da separação entre essas diferentes faixas. A separação dos estados em grupos de renda e de nível de preço relativo permite comparações que exploram separadamente cada um desses efeitos. A subseção a seguir esclarece a estratégia empírica adotada.

\subsection{Equação estimada para a demanda por álcool hidratado (segundo estágio)}

A seguinte equação de demanda, com forma funcional de duplo-logaritmo, foi estimada para a demanda por álcool hidratado:

$$
\begin{aligned}
& \operatorname{lqah}_{\text {it }}=\beta_{0}+\beta_{1} \Delta \mathrm{d} 1^{*} \operatorname{lpah}_{\text {it }}+\beta_{2} \Delta \mathrm{d} 2^{*} \operatorname{lpah}_{\text {it }}+ \\
& \beta_{3} \Delta \mathrm{d} 3^{*}{ }^{*} \mathrm{pah}_{\mathrm{it}}+\beta_{4} \Delta \mathrm{d} 4^{*}{ }^{\mathrm{lpah}} \mathrm{ph}_{\mathrm{it}}+\beta_{5} \Delta \text { lren_pc } \mathrm{c}_{\mathrm{it}}+ \\
& \beta_{6} \Delta \text { lfrota_p } \mathrm{c}_{\mathrm{it}}+\beta_{7} \Delta \mathrm{d} 1^{*} \operatorname{lpg}_{\text {it }}+\beta_{8} \Delta \mathrm{d} 2^{*} \operatorname{lpg}_{\text {it }}+ \\
& \beta_{9} \Delta \mathrm{d} 3^{*} \operatorname{lpg}_{\text {it }}+\beta_{10} \Delta \mathrm{d} 4^{*} \operatorname{lpg}_{\mathrm{it}}+\theta \Delta \mathrm{dm}_{\mathrm{it}}+ \\
& \phi \Delta \mathrm{da}_{\mathrm{it}}+\Delta \mathrm{u}_{\mathrm{it}}
\end{aligned}
$$

em que o símbolo $\Delta$ indica a primeira diferença das variáveis, $i$ indica o estado e $t$, o momento do tempo; lqah é o logaritmo do consumo de álcool hidratado per capita; lpah é o logaritmo do preço do álcool hidratado; lpg é o logaritmo do preço da gasolina; lren_pc é o logaritmo do consumo de energia per capita, como proxy da renda; $d 1$ é uma variável binária igual a 1 para os estados classificados como ricos e cujo preço relativo etanol/ gasolina tem média entre $65 \%$ e $75 \%$; d2 é uma 
Figura 4. Paridade etanol-gasolina e rendimento médio mensal por UF (2001-2009)

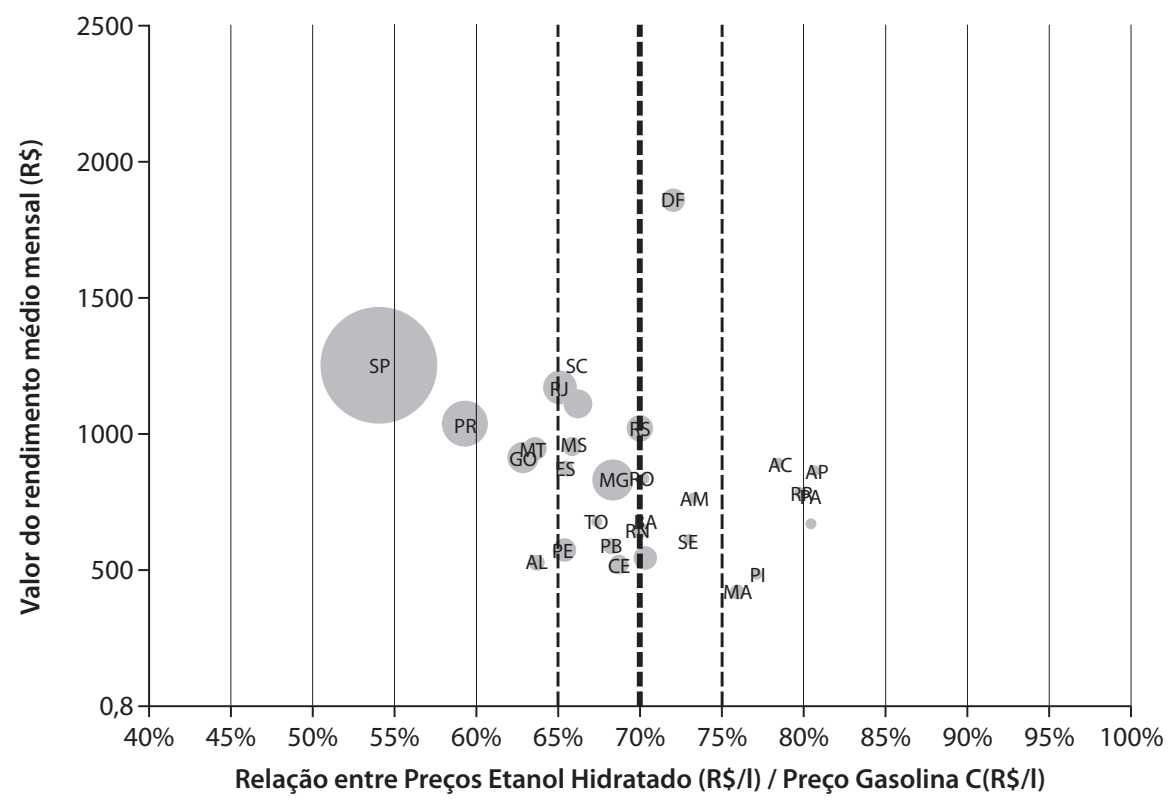

Nota: As bolhas são proporcionais ao consumo de etanol de jul/2001 até dez/2009. Os preços foram expressos em Reais de dez/2009. A linha pontilhada mais grossa (70\%) representa paridade etanol-gasolina e as duas linhas pontilhadas mais finas delimitam as faixas entre $65 \%$ e $75 \%$.

Fonte: IBGE - Pesquisa Nacional por Amostra de Domicílios e ANP. Elaboração própria.

variável binária igual a 1 para os estados classificados como pobres e cujo preço relativo etanol/ gasolina tem média entre $65 \%$ e $75 \%$; d3 é uma variável binária igual a 1 para os estados classificados como ricos e cujo preço relativo etanol/ gasolina tem média fora da faixa entre $65 \%$ e $75 \%$; $d 4$ é uma variável binária igual a 1 para os estados classificados como pobres e cujo preço relativo etanol/gasolina tem média fora da faixa entre $65 \%$ e $75 \%$; lfrota é o logaritmo da frota total de veículos movidos a etanol e flex per capita; $\mathrm{dm}$ é um vetor de 11 variáveis dummies de mês (janeiro excluído) e, finalmente; da é um vetor de dummies de ano (último ano de cada período de tempo foi excluído). Vale destacar que as dummies de faixa e de renda foram calibradas para cada período estudado.

\subsection{Variáveis instrumentais para a estimação da demanda por álcool hidratado}

Como variáveis instrumentais para o preço do etanol foram selecionadas inicialmente três variáveis de custo (ou deslocadores de oferta): o preço da ureia e do calcário e o preço externo do açúcar. Tal escolha foi submetida a testes, uma vez que instrumentos fracos (isto é, pouco correlacionados com a variável endógena) fazem com que a distribuição normal forneça uma aproximação insatisfatória para a distribuição amostral do estimador de mínimos quadrados em dois estágios, mesmo que o tamanho da amostra seja grande. Para evitar instrumentos que poderiam gerar um estimador viesado, foram realizadas estimativas por meio do método dos momentos generalizados (2step-GMM), e os instrumentos foram testados a partir da estatística Wald $\mathrm{F}$ de Kleibergen-Paap.

Os resultados dos testes para o conjunto de três instrumentos acima citados não foram satisfatórios. Como alternativa, foram utilizados os preços de regiões vizinhas. Segundo Huse e Salvo (2005), quando um produto é vendido em diversas regiões, podemos utilizar os preços em outras regiões como instrumentos para o preço em determinada região. O pressuposto é que 
os preços de um mesmo produto em diferentes regiões têm um componente de custos comum a todas as regiões e um componente não observado de demanda específico para cada região.

Assim sendo, os instrumentos usados para o preço do etanol hidratado em cada estado foram: o preço médio do álcool hidratado dos estados vizinhos, o preço do açúcar no mercado externo e o preço da ureia, ressaltando-se que todos foram interados com as variáveis binárias de renda-faixa. Além disso, o preço internacional do petróleo, também interado com as variáveis binárias de renda-faixa, foi usado como instrumento para o preço da gasolina. Como poderá ser visto na sexta seção, o teste de sobre identificação de J Hansen foi implementado em todas as estimações.

\section{Os dados}

O consumo de etanol hidratado por estado utilizado neste estudo corresponde ao valor em $\mathrm{m}^{3}$ (convertidos em litros) informado pelas distribuidoras de combustíveis à ANP. Os preços médios mensais (preços constantes dez/2009), em R\$/litro, são coletados na bomba também pela ANP. Estes foram transformados em valores reais utilizando-se o IGP-DI como deflator.

Como proxy para renda foi utilizado o consumo de energia elétrica em quantidade de GWh por região fornecido pela Eletrobrás, após a experimentação com outras proxies. Destaca-se que, na estimação do painel nacional, em virtude da ausência de dados representativos para renda estadual em bases mensais, foi utilizada a renda regional para inferir o crescimento mês a mês, o que implica a imposição de uma tendência regional de crescimento mensal da renda. A população dos estados brasileiros, utilizada para construir as variáveis per capita, é estimada pelo IBGE.

Para o cálculo da frota foram utilizados os dados de licenciamento de veículos fornecidos pela Associação Nacional dos Fabricantes de Veículos Automotores (Anfavea), que divulga mensalmente o número de veículos automotores vendidos por tipo de veículo (automóveis e comerciais leves, nacionais e importados) e de combustível (gasolina, etanol e flex-fuel). A função de sucateamento, que estabelece o percentual dos veículos sucateados em função da idade, limita a vida máxima do veículo a 40 anos (480 meses) e é uma função Gompertz ${ }^{5}$.

Com relação às variáveis instrumentais, o preço do açúcar no mercado internacional corresponde à cotação do contrato desse produto na Bolsa de Futuros (NYBOT), primeiro vencimento - extraído da Bloomberg. Esses preços foram transformados em moeda nacional utilizando-se a taxa de câmbio nominal informada pelo Banco Central e, depois, transformados em valores reais utilizando-se o IGP-DI como deflator.

O preço real (constante em dez/2009) da ureia foi obtido no banco de dados do Instituto de Economia Agrícola (IEA) da Secretaria de Agricultura e Abastecimento do Estado de São Paulo (SAA).

Por fim, o preço internacional do petróleo corresponde à cotação do contrato futuro de petróleo bruto light sweet da Divisão NYMEX (primeiro vencimento) obtido na Bloomberg. Esses preços também foram transformados em moeda nacional utilizando-se a taxa de câmbio nominal e depois transformados em valores reais por meio do IGP-DI. A Tabela 2, a seguir, apresenta as estatísticas descritivas de todas as variáveis utilizadas no trabalho e também do consumo de gasolina.

\section{Resultados}

A Tabela 3 apresenta os resultados da estimação pelo método dos momentos generalizados usando variáveis instrumentais (2step GMM). Todas as elasticidades estimadas apresentam o sinal esperado pela teoria - negativo para as elasticidades próprias e positivo para as elasticidades cruzadas - e valores significativos ao nível de $1 \%$. Além disso, os testes de sobreidentificação, subi-

5 A função utilizada corresponde a $S(t)=\exp [-\exp (a+b$ (t))], em que $S$ (t) é a fração de veículos sucateada na idade t e t é a idade do veículo. Os parâmetros (a e b) utilizados foram os informados no trabalho do Ministério dos Transportes de 2006 para sucateamento da frota no Brasil. 
Tabela 2. Estatísticas descritivas das variáveis utilizadas no trabalho

\begin{tabular}{|c|c|c|c|c|c|c|}
\hline Variável & Obs & Média & D. Padrão & Mín. & Máx. & $\mathrm{CV}$ \\
\hline Consumo de gasolina & 2754 & 73.023 .155 & 113.535 .064 & 1.068 .000 & 664.457 .344 & $155 \%$ \\
\hline Consumo de álcool hidratado & 2754 & 22.960 .691 & 75.159 .988 & 25.000 & 819.605 .504 & $327 \%$ \\
\hline Preço da gasolina & 2754 & 2,90 & 0,28 & 2,32 & 3,75 & $10 \%$ \\
\hline Preço do álccol hidratado & 2754 & 1,99 & 0,32 & 0,99 & 3,10 & $16 \%$ \\
\hline Preço do açúcar no mercado externo & 2754 & 29,76 & 7,27 & 17,54 & 46,32 & $24 \%$ \\
\hline Preço da ureia & 2754 & 1463,17 & 196,94 & 1127,83 & 2091,67 & $13 \%$ \\
\hline Preço internacional de petróleo & 2754 & 149,17 & 29,11 & 85,14 & 217,68 & $20 \%$ \\
\hline Frota de veículos flex & 2754 & 2.446 .015 & 2.932 .864 & - & 9.591 .690 & $120 \%$ \\
\hline Frota de veículos etanol & 2754 & 2.223 .016 & 437.845 & 1.488 .652 & 2.996 .174 & $20 \%$ \\
\hline Frota de veículos gasolina & 2754 & 15.356 .181 & 678.111 & 14.036 .147 & 16.295 .553 & $4 \%$ \\
\hline População dos estados & 2754 & 6.731 .185 & 8.014 .775 & 336.423 & 42.019 .122 & $119 \%$ \\
\hline Consumo de energia & 2754 & 5.055 & 4.546 & 1.094 & 18.500 & $90 \%$ \\
\hline
\end{tabular}

Fonte: Elaboração própria. Preços em moeda constante.

Tabela 3. Resultados das equações estimadas para a demanda por etanol

\begin{tabular}{|c|c|c|}
\hline Período & jul/2001 - ago/2006 & set/2006 - dez/2009 \\
\hline \multicolumn{3}{|l|}{ 2-Step GMM estimation } \\
\hline \multicolumn{3}{|l|}{ Variável dependente: $\Delta$ lqah_pc (qde etanol) } \\
\hline \multirow{2}{*}{$\Delta$ (d1*lpah) - Rico dentro da faixa } & $-1,2618^{* * *}$ & $-2,2449 * * *$ \\
\hline & $(0,1496)$ & $(0,4510)$ \\
\hline \multirow{2}{*}{$\Delta(\mathrm{d} 2 * 1 p a h)-$ Pobre dentro da faixa } & $-1,5897^{* * *}$ & $-2,3048^{* * *}$ \\
\hline & $(0,1630)$ & $(0,3198)$ \\
\hline \multirow{2}{*}{$\Delta\left(\mathrm{d} 3^{*} \mathrm{lpah}\right)-$ Rico fora da faixa } & $-1,0281^{* * *}$ & $-0,7805^{* * *}$ \\
\hline & $(0,1890)$ & $(0,1878)$ \\
\hline \multirow{2}{*}{$\Delta\left(\mathrm{d} 4^{*} \mathrm{lpah}\right)-$ Pobre fora da faixa } & $-1,3800^{* * *}$ & $-1,9017^{* * *}$ \\
\hline & $(0,4254)$ & $(0,4754)$ \\
\hline \multirow{2}{*}{$\Delta$ lren_pc } & $0,4180^{* * *}$ & 0,1595 \\
\hline & $(0,1303)$ & $(0,1307)$ \\
\hline \multirow{2}{*}{$\Delta$ lfrota (frota etanol+flex) } & $1,5839^{* * *}$ & $4,0566^{* * *}$ \\
\hline & $(0,3129)$ & $(0,7809)$ \\
\hline \multirow{2}{*}{$\Delta\left(\mathrm{d} 1^{*} \operatorname{lpg}\right)-$ Rico dentro da faixa } & $0,6351^{* * *}$ & $2,1854^{* * *}$ \\
\hline & $(0,2210)$ & $(0,6157)$ \\
\hline \multirow{2}{*}{$\Delta(\mathrm{d} 2 * \operatorname{lpg})-$ Pobre dentro da faixa } & $1,1058^{* * *}$ & $1,6558^{* * *}$ \\
\hline & $(0,2083)$ & $(0,3173)$ \\
\hline \multirow{2}{*}{$\Delta\left(\mathrm{d} 3^{*} \operatorname{lpg}\right)-$ Rico fora da faixa } & $0,5599 * * *$ & $1,0898^{* * *}$ \\
\hline & $(0,2072)$ & $(0,3995)$ \\
\hline \multirow{2}{*}{$\Delta\left(\mathrm{d} 4^{*} \mathrm{lpg}\right)-$ Pobre fora da faixa } & $0,5235^{* * *}$ & $2,8341^{* * *}$ \\
\hline & $(0,3038)$ & $(0,5043)$ \\
\hline \multirow[t]{2}{*}{ Constante } & $-0,0014$ & $0,0666^{* * *}$ \\
\hline & $(0,0046)$ & $(0,0183)$ \\
\hline R2 Centrado & 0.2311 & 0.4317 \\
\hline Número de observações & 1647 & 1080 \\
\hline Underidentification test: Kleibergen-Paap LM stat & $64,654(\mathrm{p}=0,000)$ & $53,551(\mathrm{p}=0,000)$ \\
\hline Kleibergen-Paap rk Wald F statistic & 33,449 & 8,121 \\
\hline Hansen J statistic (p-valor) & 0,7462 & 0.8184 \\
\hline BIC & -909.568 & -1767.007 \\
\hline
\end{tabular}

Notas: (i) ${ }^{*}=$ significativo a $10 \%,{ }^{* *}=$ significativo a $5 \% \mathrm{e}^{* * *}=$ significativo a $1 \%$; (ii) Os valores entre parênteses correspondem aos desvios padrão; (iii) as equações foram estimadas incluindo as variáveis binárias de mês e ano.

Fonte: Estimações dos autores. 
dentificação e de instrumentos fracos apresentam resultados satisfatórios.

Conforme também esperado, as elasticidades estimadas aumentaram de magnitude no segundo período estudado, em que a participação dos carros com tecnologia flex-fuel é mais expressiva. Das oito elasticidades estimadas em cada período, a única exceção corresponde à elasticidade-preço própria da demanda por etanol dos estados ricos e fora da faixa de paridade entre $65 \%$ e $75 \%$ (d3*lpah), o que não chega a ser surpreendente, visto que, conforme argumentado, em estados situados fora da faixa de paridade a existência de uma frota flex-fuel não deve apresentar efeito relevante. Além disso, também conforme o esperado, tanto a renda per capita quanto a participação de carros flex-fuel e etanol têm efeito positivo sobre a demanda.

A Tabela 4 resume a estrutura das variáveis binárias criadas, descritas na quarta seção deste artigo, apenas para facilitar a interpretação dos resultados.

As regressões também foram estimadas admitindo correlação espacial. Foi usado o modelo de clusters robusto proposto por Cameron, Gelbach e Miller (2006), em que os desvios padrão e as estatísticas são robustos para qualquer padrão de correlação dentro dos grupos (ou clusters) definidos. Os clusters foram definidos do modo mais usual, em que as estatísticas são robustas tanto para a correlação entre unidades federativas em cada período (correlação espacial), quanto para a correlação ao longo do tempo em cada unidade federativa (autocorrelação temporal dos resíduos).

Os resultados obtidos podem ser vistos na Tabela A3 do anexo estatístico e não diferem significativamente dos resultados das regressões já estimadas, não alterando nenhuma das conclusões. $\mathrm{O}$ sinal, a magnitude e a significância dos coeficientes permanecem praticamente inalterados e, por este motivo, são remetidos ao anexo estatístico.

Os resultados das Tabelas 3 e A3 indicam uma segunda regularidade, referente ao efeito da renda sobre a magnitude das elasticidades. Para estados dentro da mesma classificação de paridade dos preços, as elasticidades-preço próprias são maiores em magnitude para os estados pobres em comparação com os estados ricos ( $d 2$ versus $d 1$ e $d 4$ versus $d 3$ ). Tais diferenças, porém, em alguns casos são aparentemente pequenas e o padrão não é tão claro para as elasticidades cruzadas. Assim sendo, foram realizados testes de desigualdade entre os coeficientes para identificar desigualdades estatisticamente significativas, cujos resultados são apresentados na Tabela 5. A notação usada para definir as hipóteses nulas se baseia na equação apresentada na seção 4(a) deste artigo.

Tabela 4. Estrutura das variáveis binárias de renda e faixa de paridade dos preços

\begin{tabular}{lcc}
\hline & Dentro da faixa: $\mathbf{6 5 \%}$ a 75\% & Fora da faixa: $<\mathbf{6 5 \%}$ ou $>\mathbf{7 5 \%}$ \\
\hline Estados ricos & $\mathrm{d} 1$ & $\mathrm{~d} 3$ \\
Estados pobres & $\mathrm{d} 2$ & $\mathrm{~d} 4$ \\
\hline
\end{tabular}

Fonte: Estimações dos autores.

Tabela 5. Comparando elasticidades entre estados ricos e pobres com a mesma classificação de paridade dos preços

\begin{tabular}{cc}
\hline \multicolumn{2}{c}{ Estados com preço relativo médio dentro da faixa de 65\% a 75\% } \\
\hline Elasticidade Própria $\left(\mathrm{H}_{0}:-\beta_{1}>=-\beta_{2}\right)$ & Elasticidade Cruzada $\left(\mathrm{H}_{0}: \beta_{7}>=\beta_{8}\right)$ \\
p-valor do primeiro período $=0.055$ & p-valor do primeiro período $=0.050$ \\
p-valor do segundo período $=0.4566$ & p-valor do segundo período $=0.890$ \\
\hline Estados com preço relativo médio fora da faixa de 65\% a 75\% \\
\hline Elasticidade Própria $\left(\mathrm{H}_{0}:-\beta_{3}>=-\beta_{4}\right)$ & Elasticidade Cruzada $\left(\mathrm{H}_{0}: \beta_{9}>=\beta_{10}\right)$ \\
p-valor do primeiro período $=0.2228$ & p-valor do primeiro período $=0.4601$ \\
p-valor do segundo período $=0.0153$ & p-valor do segundo período $=0.0036$ \\
\hline
\end{tabular}

Fonte: Estimações dos autores. 
Tabela 6. Comparando estados com diferente classificação de paridade de preços e mesma classificação de renda per capita

\begin{tabular}{cc}
\hline \multicolumn{2}{c}{ Estados classificados como ricos } \\
\hline Elasticidade Própria $\left(\mathrm{H}_{0}:-\beta_{1}<=-\beta_{3}\right)$ & Elasticidade Cruzada $\left(\mathrm{H}_{0}: \beta_{7}<=\beta_{9}\right)$ \\
p-valor do primeiro período $=0.1599$ & p-valor do primeiro período $=0.4012$ \\
p-valor do segundo período $=0.00075$ & p-valor do segundo período $=0.0638$ \\
\hline \multicolumn{2}{c}{ Estados classificados como pobres } \\
\hline Elasticidade Própria $\left(\mathrm{H}_{0}:-\beta_{2}<=-\beta_{4}\right)$ & Elasticidade Cruzada $\left(\mathrm{H}_{0}: \beta_{8}<=\beta_{10}\right)$ \\
p-valor do primeiro período $=0.3180$ & p-valor do primeiro período $=0.0500$ \\
p-valor do segundo período $=0.2382$ & p-valor do segundo período $=0.950$ \\
\hline
\end{tabular}

Fonte: Estimações dos autores.

Apesar de todas as elasticidades próprias serem maiores em magnitude para os estados classificados como pobres, mantida a faixa de paridade de preços constante, a diferença não é estatisticamente significativa em todos os casos, sendo significativa ao nível de $5 \%$ no primeiro período para estados com preço relativo dentro da faixa de $65 \%$ a $75 \%$, e no segundo período para estados com preço relativo fora dessa faixa. Para as elasticidades cruzadas, esse padrão se mantém ${ }^{6}$.

Os resultados constantes na Tabela 3 revelam ainda que, para estados dentro da mesma classificação de renda per capita, as elasticidades preço próprias são maiores em magnitude para os estados com preço relativo médio dentro da faixa de $65 \%$ a $75 \%$ em comparação com os estados com preço relativo médio fora dessa faixa ( $d 1$ versus $d 3$ e $d 2$ versus $d 4$ ). O mesmo ocorre com relação às elasticidades cruzadas, com a exceção apenas dos estados pobres no segundo período estudado. Assim sendo, foram realizados testes de desigualdade entre os coeficientes para identificar desigualdades estatisticamente significativas, cujos resultados são apresentados na Tabela 6 . Mais uma vez, a notação usada para definir as hipóteses nulas se baseia na equação apresentada na seção 4(a) deste artigo.

Apesar de todas as elasticidades-preço próprias serem maiores em magnitude para os estados com preço relativo etanol-gasolina dentro

6 Para as elasticidades cruzadas, há um caso em que a elasticidade é maior nos estados ricos em comparação com os pobres; porém, a diferença não é estatisticamente significativa. da faixa de $65 \%$ a $75 \%$, mantida a faixa de renda per capita constante, a diferença não é estatisticamente significativa em todos os casos, sendo significativa ao nível de $5 \%$ no segundo período para estados classificados como ricos. O mesmo ocorre com a elasticidade-preço cruzada, sendo a diferença também significativa no primeiro período para estados classificados como pobres.

\subsection{Comparação das elasticidades estimadas com relação a outros estudos}

A Tabela 7 resume as elasticidades da demanda por etanol, estimadas para o Brasil em trabalhos anteriores para diferentes períodos de tempo. A maioria dos trabalhos utilizou o modelo de correção de erros, que permite calcular a relação de longo prazo quando as variáveis cointegram. Contudo, nem todos os trabalhos trataram diretamente o problema da endogeneidade, o que pode resultar em estimadores viesados. Além disso, os trabalhos anteriores utilizaram dados agregados para o Brasil, o que impossibilita segregar as diferenças regionais, sendo estas as duas importantes contribuições deste artigo.

Concentrando a atenção nos resultados relativos ao etanol, nota-se que alguns trabalhos anteriores, como o de Sordi (1997), estimaram elasticidades-preço próprias da demanda bastante inferiores àquelas estimadas neste trabalho. Há duas explicações plausíveis para esta divergência. Primeiro, o período de tempo investigado, quando anterior à consolidação da tecnologia flex-fuel, deve, de fato, resultar em elas- 
ticidades-preço de menor magnitude. Segundo, o não tratamento para o problema de endogeneidade gera estimativas viesadas para baixo (em módulo), subestimando a magnitude da elasticidade da demanda (DE SOUZA, PETTERINI e SILVA, 2009). É, portanto, esperado que estudos que abordam o período anterior à disseminação dos automóveis flex-fuel e/ou que não tratam diretamente do viés de simultaneidade obtenham parâmetros da demanda mais inelásticos em relação a preços. Já a elasticidade estimada por Serigati et al. (2010) é bastante próxima das estimadas neste trabalho, como era de se esperar em virtude do período de tempo investigado, sendo também consideravelmente altas as elasticidades estimadas por Freitas e Kaneko (2011), Santos e Faria (2012) e Santos (2013). Contudo, as estimativas desses autores não captam diferenças regionais aqui evidenciadas. A elasticidade-preço própria da demanda por etanol estimada neste trabalho, para o período posterior a julho de 2006, chega a ser igual a -2,305 para os estados pobres com preço relativo etanol-gasolina próximo ao valor crítico de $70 \%$. Ao mesmo tempo, para os estados ricos com preço relativo etanol-gasolina fora da faixa de $65 \%$ a $75 \%$, a elasticidade própria estimada é de $-0,781$. Vale observar, por fim, que Luchansky \& Monks (2009) também estimaram elasticidades próprias da demanda por etanol nos Estados Unidos com intervalo de variação semelhante ao obtido neste estudo, sendo a elasticidade máxima por eles projetada igual a $(-2,915)$.

\section{Conclusões}

Este artigo investigou a demanda por etanol no Brasil no período 2001-2009, levando-se em consideração as características específicas do mercado nacional de combustíveis e tendo como foco de interesse a identificação de diferenças estaduais de elasticidade-preço da demanda por etanol. Foi estimado um modelo econométrico a partir de um painel de dados estaduais mensais, no qual variáveis instrumentais foram usadas para controlar a endogeneidade na análise da demanda. $\mathrm{O}$ estudo foi feito separadamente para dois períodos distintos, tendo em vista o crescimento da frota de veículos com motores flex-fuel. Além disso, levou-se em consideração o fato de que, por motivos logísticos e tributários, o preço relativo etanol-gasolina situa-se em níveis distintos, por vezes muito acima ou abaixo do valor crítico de $70 \%$, o que mitiga o efeito substituição decorrente da tecnologia flex-fuel.

Conclui-se que a elasticidade da demanda por etanol aumentou, de modo geral, com a consolidação da tecnologia flex-fuel. Além disso, conclui-se que demanda é mais elástica em estados mais pobres em comparação com os estados mais ricos e em estados com preço relativo etanol-gasolina próximo ao valor crítico de $70 \%$. Esses resultados se contrapõem àqueles obtidos por Salvo e Huse (2013), que, por meio de dados ao nível do indivíduo, também identificam diferenças regionais, porém, decorrentes da heterogeneidade dos consumidores. O presente estudo

Tabela 7. Elasticidades da demanda por etanol estimadas em estudos anteriores para o Brasil

\begin{tabular}{lccc}
\hline \multicolumn{1}{c}{ Autor } & Elasticidade-preço & Elasticidade-cruzada gasolina & Elasticidade-renda \\
\hline Sordi (1997) & $-0,15$ & & 0,31 \\
Pontes (2009) & $-0,934$ & 1,374 & 1,255 \\
Serigati, Correia e Perosa (2010)* & $-2,18$ & 1,98 & - \\
Farina et al. (2010) & $-1,23$ & 1,45 & - \\
Freitas e Kaneko (2011) & $-1,413$ & 0,948 & - \\
Santos e Faria (2012) & $-1,113$ & 1,268 & 0,138 \\
Santos (2013) & $-1,252$ & 1,182 & 0,551 \\
\hline
\end{tabular}

* Resultado do 'modelo 1', para o período pós-flex.

Fonte: Resultados extraídos dos estudos originais. 
mostra que, mesmo em um contexto de homogeneidade de consumidores, há fortes motivos para diferenças regionais na demanda por combustíveis, decorrentes da infraestrutura logística, que afeta o preço relativo entre etanol e gasolina, e do nível de renda per capita.

Estimativas obtidas em outros trabalhos para o mesmo período não captam diferenças regionais significativas e importantes aqui evidenciadas. A elasticidade-preço própria da demanda por etanol estimada neste trabalho, para o período posterior a julho de 2006, chega a ser igual a -2,305 para os estados pobres com preço relativo etanol-gasolina próximo ao valor crítico de $70 \%$. Ao mesmo tempo, para os estados ricos com preço relativo etanol-gasolina fora da faixa de $65 \%$ a $75 \%$, a elasticidade própria estimada é de -0,781.

Os resultados sugerem importantes implicações para as políticas tributária e de infraestrutura logística, as quais, ao afetarem o nível de preços relativos entre etanol e gasolina, afetam substancialmente o modo de funcionamento do mercado de combustíveis, em particular a sensibilidade da demanda com relação às variações de preço.

\section{Referências bibliográficas}

ANDERSON, S. T. The demand for ethanol as a gasoline substitute. Journal of Environmental Economics and Management, Elsevier, v. 63, n. 2, p. 151-168, 2012.

\section{ANUÁRIO ESTATÍSTICO DA INDÚSTRIA AUTOMOBILÍSTICA BRASILEIRA 2009. São Paulo: Associação Nacional dos Fabricantes de Veículos Automotores - Anfavea, 2009. \\ BACCHI, M. R. P. Formação de preços no setor sucroalcooleiro da região centro-sul do Brasil: relação com o mercado de combustível fóssil. In: XXXIII Encontro Nacional de Economia. Associação Nacional dos Centros de Pós-Graduação em Economia, Natal - RN, 2005.}

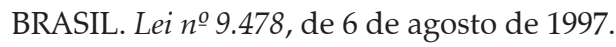

. Ministério da Ciência e Tecnologia. Emissões de gases de efeito estufa por fontes móveis no setor energético. Primeiro inventário brasileiro de emissões antrópicas de gases de efeito estufa - Relatórios de referência, 2006.
BURNQUIST, H. L. e BACCHI, M. R. P. A Demanda por gasolina no Brasil: uma análise utilizando técnicas de co-integração. In: XL Congresso Brasileiro de Economia e Sociologia Rural, 2002, Equidade e Eficiência na Agricultura Brasileira. Passo Fundo, RS, 2002.

CAMERON, A. C., GELBACH J. B. e MILLER, D. L. Bootstrap-based improvements for inference with clustered errors, Working Papers 06-21, University of California at Davis, Department of Economics, 2006.

CHICHILNISKY, G. Global Property Rights: The Kyoto Protocol and the Knowledge Revolution, Institut du Development Durable et Relations Internationales (IDDRI) Working Paper No 09/2006, Ecole Polytechnique, Paris, France, 2006.

DesOUZA, S. A., PETTERINI, F. C. e MIRO, V. H. A tributação nas vendas de automóveis no Brasil: quem paga a maior parte da conta? Revista Economia, v. 11, n. 3, p. 559-596, set./dez. 2010.

FARINA, E. M. M. Q., VIEGAS, C., PEREDA, P. e GARCIA, C. Mercado e concorrência do etanol. In: SOUZA, E. L. e MACEDO, I. C. (Org.). Etanol e Bioeletricidade: a cana-de-açúcar no future da matriz energética. São Paulo: ÚNICA, p. 226-259, 2010.

FREITAS, L. C. e KANEKO, S. Ethanol demand under the flex-fuel technology regime in Brazil. Energy Economics, v. 33, n. 6, p. 1146-1154, 2011.

GREENPEACE. Energy [r]evolution. Version 3. 2010. Disponível em: <http://www.greenpeace.org/ international/Global/international/publications/ climate/2010/summary.pdf $>$.

HUSE, C. e SALVO, A. Métodos empíricos em organização industrial e aplicações ao antitruste. In: Seminário Estudos em Métodos Quantitativos Aplicados a Defesa da Concorrência e a Regulação Econômica. SDE, IPEA, ANPEC, Brasília, 2005.

LUCHANSKY, M. S. e MONKS, J. Supply and Demand Elasticities for the United States Ethanol Market. Energy Economics, v. 31, n. 3, p. 403-410, 2009.

MAISTRO, M. C. M. e ASAI, G. A. Álcool Combustível: Do Carro a álcool ao carro Flex. Jornal de Piracicaba, 2006. Acessado em: <http://cepea.esalq.usp.br/pdf/ Cepea_artigo_flex.pdf $>$.

Nota Técnica ANP 011/2001. Combustíveis no Brasil: Políticas de Preço e Estrutura Tributária, 2001.

RAMANATHAN, R. Short and long-run elasticities of gasoline demand in India: an empirical analysis using co-integration techiniques. Energy Economics, v. 21, n. 4, p. 321-330, 1999. 
RODRÍGUEZ, M. F. Estimación de la demanda de combustibles en República Dominicana. Secretariado Técnico de la Presidência - Unidad de Análisis Econômico. República Dominicana: Texto de Discusión 6, 2006.

SALVO, A. e HUSE, C. Build it, but will they come? Evidence from consumer choice between gasoline and sugarcane ethanol. Journal of Environmental Economics and Management. Available online 6 May 2013.

SANTOS, G. F. Fuel demand in Brazil in a dynamic panel data approach. Energy Economics, v. 36, p. 229-240, 2013.

. e FARIA, W. R. Spatial Panel Data Models and Fuel Demand in Brazil. Texto para Discussão Nereus 10-2012, Universidade de São Paulo. 2012.

SERIGATI, F. C., CORREIA, L. B. e PEROSA, B. B. O impacto dos veículos flex-fuel sobre o mercado de combustíveis no Brasil. In: XLVIII Congresso Brasileiro de Economia, Administração e Sociologia Rural, 2010,
Tecnologias, Desenvolvimento e Integração Social. Campo Grande, MS. 2010. Disponível em: < http://www.sober. org.br/palestra/15/159.pdf>. Acesso em: 08 nov. 2010.

SORDI, J. C. Os efeitos dos custos de transporte na liberação dos preços: o caso do álcool hidratado no Brasil. 1997. 159f. Dissertação de Mestrado. Universidade Estadual de Maringá, Maringá, Brasil.

STOCK, J. H., WRIGHT J. H. e YOGO, M. A survey of weak instruments and weak identification in generalized method of moments. American Statistical Association Journal of Business \& Economic Statistics, v. 20, n. 4, p. 518-529, 2002.

União da Agroindústria Canavieira de São Paulo UNICA. Disponível em: <http://www.unica.com.br>.

WWF. The Energy Report: 100\% Renewable Energy by 2050. Relatório lançado em fevereiro de 2011. Disponível em: $\quad<$ http://assets.panda.org/downloads/101223 energy_report_final_print_2.pdf $>$. 
Tabela A1. Classificação dos estados de acordo com a renda per capita*

\begin{tabular}{|c|c|c|c|c|c|c|c|c|c|c|c|}
\hline \multirow{2}{*}{\multicolumn{2}{|c|}{ Estado }} & \multicolumn{4}{|c|}{ jul. 2001 até ago. 2006} & \multirow{3}{*}{$\frac{\mathrm{CV}}{2.6 \%}$} & \multicolumn{4}{|c|}{ set. 2006 até dez. 2009} & \multirow{3}{*}{$\frac{\mathrm{CV}}{1.8 \%}$} \\
\hline & & \multirow{2}{*}{$\begin{array}{c}\text { Média } \\
870.668\end{array}$} & \multirow{2}{*}{$\begin{array}{c}\text { DP } \\
22.597\end{array}$} & \multicolumn{2}{|c|}{ Int. Conf. - 95\% } & & \multirow{2}{*}{$\begin{array}{c}\text { Média } \\
935.353\end{array}$} & \multirow{2}{*}{$\frac{\text { DP }}{16.833}$} & \multicolumn{2}{|c|}{ Int. Conf. 95\% } & \\
\hline 1 & $\mathrm{AC}$ & & & 826.346 & 914.990 & & & & 902.323 & 968.382 & \\
\hline 2 & $\mathrm{AL}$ & 477.657 & 7.052 & 463.824 & 491.489 & $1.5 \%$ & 613.005 & 3.650 & 605.844 & 620.166 & $0.6 \%$ \\
\hline 3 & $\mathrm{AP}$ & 883.110 & 13.531 & 856.570 & 909.649 & $1.5 \%$ & 850.863 & 9.671 & 831.886 & 869.840 & $1.1 \%$ \\
\hline 4 & $\mathrm{AM}$ & 744.340 & 11.161 & 722.450 & 766.231 & $1.5 \%$ & 803.923 & 4.404 & 795.282 & 812.564 & $0.5 \%$ \\
\hline 5 & $\mathrm{BA}$ & 512.676 & 5.481 & 501.926 & 523.425 & $1.1 \%$ & 607.328 & 4.260 & 598.968 & 615.687 & $0.7 \%$ \\
\hline 6 & $\mathrm{CE}$ & 494.657 & 5.147 & 484.561 & 504.752 & $1.0 \%$ & 566.148 & 5.232 & 555.881 & 576.414 & $0.9 \%$ \\
\hline 7 & DF & 1750.692 & 17.362 & 1716.639 & 1784.744 & $1.0 \%$ & 2037.315 & 13.308 & 2011.203 & 2063.427 & $0.7 \%$ \\
\hline 8 & ES & 842.232 & 8.843 & 824.888 & 859.577 & $1.0 \%$ & 933.993 & 5.415 & 923.367 & 944.618 & $0.6 \%$ \\
\hline 9 & GO & 878.692 & 6.892 & 865.174 & 892.210 & $0.8 \%$ & 979.045 & 5.618 & 968.021 & 990.069 & $0.6 \%$ \\
\hline 10 & MA & 455.623 & 6.518 & 442.839 & 468.406 & $1.4 \%$ & 551.908 & 6.639 & 538.881 & 564.935 & $1.2 \%$ \\
\hline 11 & MT & 914.527 & 10.848 & 893.251 & 935.804 & $1.2 \%$ & 995.993 & 12.548 & 971.372 & 1020.613 & $1.3 \%$ \\
\hline 12 & MS & 903.239 & 9.256 & 885.083 & 921.394 & $1.0 \%$ & 1050.425 & 9.157 & 1032.458 & 1068.392 & $0.9 \%$ \\
\hline 13 & MG & 788.823 & 7.304 & 774.497 & 803.148 & $0.9 \%$ & 903.400 & 5.494 & 892.619 & 914.181 & $0.6 \%$ \\
\hline 14 & PR & 987.495 & 6.815 & 974.128 & 1000.862 & $0.7 \%$ & 1125.690 & 7.228 & 1111.507 & 1139.873 & $0.6 \%$ \\
\hline 15 & PB & 537.447 & 5.865 & 525.943 & 548.951 & $1.1 \%$ & 675.550 & 5.620 & 664.523 & 686.577 & $0.8 \%$ \\
\hline 16 & PA & 652.894 & 10.637 & 632.031 & 673.756 & $1.6 \%$ & 701.418 & 4.261 & 693.057 & 709.778 & $0.6 \%$ \\
\hline 17 & PE & 554.147 & 6.291 & 541.807 & 566.487 & $1.1 \%$ & 609.138 & 5.005 & 599.316 & 618.959 & $0.8 \%$ \\
\hline 18 & PI & 443.000 & 6.084 & 431.066 & 454.934 & $1.4 \%$ & 563.393 & 4.325 & 554.906 & 571.879 & $0.8 \%$ \\
\hline 19 & RJ & 1143.376 & 12.057 & 1119.727 & 1167.025 & $1.1 \%$ & 1229.728 & 8.263 & 1213.515 & 1245.940 & $0.7 \%$ \\
\hline 20 & $\mathrm{RN}$ & 622.710 & 8.722 & 605.603 & 639.817 & $1.4 \%$ & 692.095 & 4.376 & 683.508 & 700.682 & $0.6 \%$ \\
\hline 21 & RS & 989.195 & 8.038 & 973.429 & 1004.962 & $0.8 \%$ & 1077.822 & 7.437 & 1063.230 & 1092.415 & $0.7 \%$ \\
\hline 22 & $\mathrm{RO}$ & 844.165 & 11.309 & 821.983 & 866.346 & $1.3 \%$ & 835.808 & 9.050 & 818.050 & 853.565 & $1.1 \%$ \\
\hline 23 & $R R$ & 749.286 & 16.009 & 717.885 & 780.686 & $2.1 \%$ & 856.038 & 13.902 & 828.759 & 883.316 & $1.6 \%$ \\
\hline 24 & SC & 1056.723 & 9.236 & 1038.607 & 1074.839 & $0.9 \%$ & 1201.520 & 9.032 & 1183.798 & 1219.242 & $0.8 \%$ \\
\hline 25 & SE & 575.106 & 4.610 & 566.065 & 584.148 & $0.8 \%$ & 682.388 & 5.671 & 671.261 & 693.515 & $0.8 \%$ \\
\hline 26 & SP & 1249.898 & 15.551 & 1219.397 & 1280.399 & $1.2 \%$ & 1269.780 & 4.701 & 1260.556 & 1279.004 & $0.4 \%$ \\
\hline 27 & $\mathrm{TO}$ & 629.053 & 5.306 & 618.647 & 639.460 & $0.8 \%$ & 763.843 & 7.605 & 748.920 & 778.765 & $1.0 \%$ \\
\hline Médi & cional & 798.20 & 7.26 & 783.96 & 812.44 & $0.9 \%$ & 893.07 & 9.51 & 874.41 & 911.73 & $1.1 \%$ \\
\hline
\end{tabular}

* Em cinza estão grifados os estados com renda per capita superior à média nacional, classificados como ricos.

Fonte: Instituto Brasileiro de Geografia e Estatística (IBGE) e Eletrobrás. 
Tabela A2. Preço relativo etanol-gasolina no Brasil: 2001-2009

\begin{tabular}{|c|c|c|c|c|c|c|c|c|}
\hline \multirow{3}{*}{$\frac{\text { Estado }}{\text { AC }}$} & \multicolumn{4}{|c|}{ jul. 2001 até ago. 2006} & \multicolumn{4}{|c|}{ set. 2006 até dez. 2009} \\
\hline & \multirow{2}{*}{$\begin{array}{c}\text { Média } \\
0,784\end{array}$} & \multirow{2}{*}{$\frac{D P}{0,012}$} & \multicolumn{2}{|c|}{ [Int. Confiança - 95\%] } & \multirow{2}{*}{$\frac{\text { Média }}{0,712}$} & \multirow{2}{*}{$\frac{D P}{0,002}$} & \multicolumn{2}{|c|}{ [Int. Confiança - 95\%] } \\
\hline & & & 0,761 & 0,807 & & & 0,707 & 0,717 \\
\hline $\mathrm{AL}$ & 0,637 & 0,006 & 0,624 & 0,649 & 0,643 & 0,006 & 0,632 & 0,655 \\
\hline $\mathrm{AP}$ & 0,807 & 0,009 & 0,789 & 0,824 & 0,808 & 0,009 & 0,790 & 0,825 \\
\hline $\mathrm{AM}$ & 0,732 & 0,009 & 0,714 & 0,749 & 0,724 & 0,005 & 0,714 & 0,734 \\
\hline $\mathrm{BA}$ & 0,703 & 0,006 & 0,691 & 0,715 & 0,645 & 0,004 & 0,637 & 0,653 \\
\hline CE & 0,687 & 0,007 & 0,674 & 0,700 & 0,681 & 0,005 & 0,671 & 0,691 \\
\hline $\mathrm{DF}$ & 0,719 & 0,007 & 0,705 & 0,734 & 0,685 & 0,007 & 0,671 & 0,700 \\
\hline ES & 0,654 & 0,009 & 0,636 & 0,672 & 0,689 & 0,004 & 0,681 & 0,697 \\
\hline GO & 0,628 & 0,009 & 0,611 & 0,646 & 0,586 & 0,007 & 0,573 & 0,599 \\
\hline MA & 0,759 & 0,008 & 0,744 & 0,774 & 0,664 & 0,005 & 0,655 & 0,674 \\
\hline MT & 0,635 & 0,007 & 0,622 & 0,649 & 0,522 & 0,010 & 0,502 & 0,541 \\
\hline MS & 0,659 & 0,007 & 0,646 & 0,672 & 0,641 & 0,004 & 0,632 & 0,649 \\
\hline MG & 0,683 & 0,009 & 0,665 & 0,701 & 0,684 & 0,005 & 0,673 & 0,695 \\
\hline PA & 0,804 & 0,010 & 0,784 & 0,825 & 0,788 & 0,007 & 0,775 & 0,802 \\
\hline PB & 0,681 & 0,007 & 0,668 & 0,695 & 0,702 & 0,006 & 0,691 & 0,713 \\
\hline PR & 0,592 & 0,009 & 0,57 & 0,610 & 0,596 & 0,006 & 0,584 & 0,608 \\
\hline PE & 0,654 & 0,006 & 0,642 & 0,666 & 0,632 & 0,006 & 0,620 & 0,643 \\
\hline PI & 0,771 & 0,008 & 0,756 & 0,786 & 0,743 & 0,007 & 0,730 & 0,757 \\
\hline $\mathrm{RN}$ & 0,699 & 0,008 & 0,683 & 0,714 & 0,680 & 0,006 & 0,670 & 0,691 \\
\hline RS & 0,700 & 0,010 & 0,681 & 0,720 & 0,696 & 0,007 & 0,683 & 0,709 \\
\hline RJ & 0,651 & 0,008 & 0,635 & 0,668 & 0,660 & 0,005 & 0,650 & 0,670 \\
\hline RO & 0,702 & 0,008 & 0,687 & 0,717 & 0,706 & 0,005 & 0,697 & 0,715 \\
\hline $\mathrm{RR}$ & 0,797 & 0,009 & 0,780 & 0,815 & 0,792 & 0,003 & 0,785 & 0,799 \\
\hline SC & 0,662 & 0,006 & 0,650 & 0,674 & 0,670 & 0,004 & 0,661 & 0,679 \\
\hline SP & 0,541 & 0,009 & 0,523 & 0,558 & 0,539 & 0,007 & 0,526 & 0,552 \\
\hline $\mathrm{SE}$ & 0,729 & 0,007 & 0,715 & 0,743 & 0,734 & 0,006 & 0,723 & 0,746 \\
\hline TO & 0,673 & 0,007 & 0,659 & 0,688 & 0,640 & 0,006 & 0,629 & 0,651 \\
\hline
\end{tabular}

Fonte: ANP. Elaboração própria. 
Tabela A3. Resultados das equações estimadas para a demanda por etanol

Modelo admitindo correlação espacial

\begin{tabular}{|c|c|c|}
\hline Período & \multirow{2}{*}{ jul/2001 - ago/2006 } & \multirow{2}{*}{ set $/ 2006-\mathrm{dez} / 2009$} \\
\hline 2-Step GMM estimation & & \\
\hline \multicolumn{3}{|l|}{ Variável dependente: $\Delta$ lqah_pc (qde etanol) } \\
\hline \multirow{2}{*}{$\Delta\left(\right.$ dummy $\left.1^{*} l p a h\right)-$ Rico dentro da faixa } & $-1,2647^{* * *}$ & $-2,3019^{* * *}$ \\
\hline & $(0,1865)$ & $(0,6074)$ \\
\hline \multirow{2}{*}{$\Delta($ dummy $2 * l p a h)-$ Pobre dentro da faixa } & $-1,5600^{* * *}$ & $-2,3197^{* * *}$ \\
\hline & $(0,2056)$ & $(0,5391)$ \\
\hline \multirow[b]{2}{*}{$\Delta$ (dummy3*lpah) - Rico fora da faixa } & $-0,9849^{* * *}$ & $-0,8249^{* * *}$ \\
\hline & $(0,1911)$ & $(0,2456)$ \\
\hline \multirow{2}{*}{$\Delta\left(\right.$ dummy $4^{*}$ lpah $)$ - Pobre fora da faixa } & $-1,3208^{* * *}$ & $-1,8762^{* * *}$ \\
\hline & $(0,3019)$ & $(0,6249)$ \\
\hline \multirow{2}{*}{$\Delta$ lren_pc } & $0,4267^{* * *}$ & 0,1811 \\
\hline & $(0,1645)$ & $(0,1596)$ \\
\hline \multirow{2}{*}{$\Delta$ lfrota_eta_flex_pc (frota etanol+flex) } & $1,5211^{* * *}$ & $4,1466^{* *}$ \\
\hline & $(0,5413)$ & $(1,9172)$ \\
\hline \multirow{2}{*}{$\Delta$ (dummy $\left.1^{*} \operatorname{lpg}\right)$ - Rico dentro da faixa } & $0,6287^{* * *}$ & $2,2639 * * *$ \\
\hline & $(0,2550)$ & $(0,7615)$ \\
\hline \multirow{2}{*}{$\Delta$ (dummy2* lpg) - Pobre dentro da faixa } & $1,0858^{* * *}$ & $1,6942^{* * *}$ \\
\hline & $(0,2014)$ & $(0,3384)$ \\
\hline \multirow{2}{*}{$\Delta$ (dummy3* $3^{*}$ pg) - Rico fora da faixa } & $0,5145^{* *}$ & $1,0942^{* * *}$ \\
\hline & $(0,2323)$ & $(0,3051)$ \\
\hline \multirow{2}{*}{$\Delta\left(\right.$ dummy $\left.4^{*} \operatorname{lpg}\right)-$ Pobre fora da faixa } & $0,4995^{*}$ & $2,7619^{* * *}$ \\
\hline & $(0,2904)$ & $(0,8044)$ \\
\hline \multirow{2}{*}{ Constante } & 0,0003 & $-0,0691$ \\
\hline & $(0,0045)$ & $(0,0457)$ \\
\hline R2 Centrado & 0.2320 & 0.4306 \\
\hline Número de observações & 1647 & 1080 \\
\hline
\end{tabular}

Notas: (i) ${ }^{*}=$ significativo a $10 \%,{ }^{* *}=$ significativo a $5 \% \mathrm{e}^{* * *}=$ significativo a $1 \%$; (ii) Os valores entre parênteses correspondem aos desvios padrão; (iii) as equações foram estimadas incluindo as variáveis binárias de mês e ano.

Fonte: Estimações dos autores. 